\title{
Elaboration and Characterization of Carbon Dots for Hydrogen Storage
}

\author{
S. Bouchear ${ }^{a, *}$, N. Bellel ${ }^{a}$ And L. Chetibi $^{b}$ \\ ${ }^{a}$ Energy Physics Laboratory, Department of Physics, Faculty of Exact Science, \\ Frères Mentouri Constantine 1 University, Constantine, 25017, Algeria \\ ${ }^{b}$ National Polytechnic School of Constantine, BP 75, A, Nouvelle ville RP, Constantine, Algeria
}

Received: 25.01.2021 \& Accepted: 25.03.2021

\author{
Doi: 10.12693/APhysPolA.139.717 \\ *e-mail: salimbouchear@yahoo.fr
}

\begin{abstract}
In the present work, carbon nanoparticles were synthesized by using a simple and cheap procedure. These nanostructures were elaborated by the electrochemical technique under various conditions. The morphological study of the carbon nanoparticles was observed by scanning electron microscopy. The Raman, the Fourier transform infrared, and X-ray photoelectron spectroscopies were used to investigate the structure of the prepared nanoparticles. The identification of carbon bonds, diameter sizes, and their distribution are exhaustively discussed. Carbon structures at the nanoscale with high surface area were observed. They are active and functional to create favorable sites for different applications such as hydrogen storage, optoelectronics or photonics
\end{abstract}

topics: carbon, nanoparticles, electrochemical, hydrogen

\section{Introduction}

Today, the term of nanocarbon is used to denote a family of carbon allotropes $[1,2]$ having nanoscale dimensions [3], and depending on the type of a three-dimensional arrangement of carbon atoms $[4,5]$. Therefore, there are new carbon materials with allotropic varieties such as: carbon nanotubes $[6,7]$, graphite, nanofibers $[8,9]$, fullerene [10], graphene [11, 12], and carbon quantum dots (CQDs), which are porous and carbonbased. They represent the most studied elements and may be used in solid storage and reversible treatment [11]. Several synthetic techniques, including the matrix method [13, 14], the etching of metal carbides $[15,16]$ and the solgel treatment $[17,18]$ have been employed to prepare and elaborate porous carbon materials. These techniques can control the pore structures in microporous $(>2 \mathrm{~nm}$ ), mesoporous (between $2 \mathrm{~nm}$ and $50 \mathrm{~nm}$ ) and macroporous (> $50 \mathrm{~nm}$ ) materials [19].

Carbon properties, such as high mechanical strength, efficient heat transfer coefficient, long life and thermodynamic kinetics that rapidly absorb and release molecules, make them materials of choice for many applications: photonics, optoelectronics, advanced electrodes, nanomedicine [20-23] and hydrogen storage [24]. In addition, carbonbased materials have the advantage of being lighter than the inorganic compounds available on the market $[25,26]$.
Many techniques of elaboration were used to prepare carbon quantum dots (CQDs). In 2004, Xu et al. [27] used an arc discharge technique to make single-walled carbon nanotubes (SWNTs). Another method, the laser ablation experimental technique, was used in 2006 to synthesize CQDs by Sun et al. [28], and in 2011, by Li et al. [29]. Also, Lei et al. [30] prepared in 2017 specimens of CQDs by using the combustion thermal method and Deng et al. [31], in 2014, used the electrochemical process to elaborate CQDs with particle size of $2.4 \mathrm{~nm}$.

In the current paper, we have used an electrochemical process because it is simple, efficient and non-cost to prepare three samples based on carbon nanostructures with different allotropies and morphologies at the nanoscale. Their characterizations were made by means of scanning electron microscopy (SEM), Raman, the Fourier transform infrared (FTIR) and X-ray photoelectron spectroscopy (XPS).

\section{Experimental}

As part of the experimental research methodology, graphite was used as a carbon source by an electrochemical technique. Two graphite rods (used as electrodes) were emerged in $400 \mathrm{ml}$ of ethanol $\left(\mathrm{C}_{2} \mathrm{H}_{5} \mathrm{OH}\right)$, while a voltage applied was applied between $50 \mathrm{~V}$ and $70 \mathrm{~V}$ by an electric generator, and the temperature changed between $30^{\circ} \mathrm{C}$ and $60^{\circ} \mathrm{C}$ for $42 \mathrm{~h}$. In Table I, different conditions of the three prepared samples are demonstrated. 
TABLE I

Different preparation conditions of the three samples.

\begin{tabular}{c|c|c}
\hline \hline Sample & Voltage applied [V] & $T\left[{ }^{\circ} \mathrm{C}\right]$ \\
\hline $\mathrm{a}$ & 70 & 60 \\
$\mathrm{~b}$ & 70 & 30 \\
$\mathrm{c}$ & 50 & 30
\end{tabular}

The samples are noted with a, b, c with reference to each part of Fig. 1. Following the preparation of the colloidal carbon particles in ethanol, they were dried on a conductive aluminum foil for their characterization.

\section{Results and discussion}

\subsection{SEM analysis}

Figure 1 displays three SEM images. It illustrates the distribution and morphology of random carbon nanoparticles with different diameters in spherical particles form. These carbon nanoparticles are interconnected and agglomerated with irregularly sized pores forming a rough surface with high and large surface area. The dispersed carbon nanoparticles and their voids on $\mathrm{Al}$ foil with such structures of high microporosity present some sites for storing hydrogen molecules. Also, the distance between nanoparticles can be used like an external site for storage.

Hydrogen can basically be adsorbed on nanocarbons in two different ways: (i) by physisorption, i.e., interacting by Van der Waals (VdW) forces, or (ii) by chemisorption, i.e., by forming a chemical bond with the carbon atoms, and the binding energy is theoretically evaluated between 0.01 and $0.06 \mathrm{eV}$ [32]. The larger the surface, the more high storage capacity we get. At low pressures and at low temperatures $(77 \mathrm{~K})$ it is assumed that the amount of hydrogen adsorbed increases by $1 \mathrm{wt} \%$ per $500 \mathrm{~m}^{2} / \mathrm{g}$ of surface area for the nanocarbon adsorbent [33].

Figure 1a shows the obtained morphology under $60{ }^{\circ} \mathrm{C}, 70 \mathrm{~V}$ for $42 \mathrm{~h}$. It shows dispersed carbon nanoparticles with the size of less than $10 \mathrm{~nm}$, which can be considered as carbon quantum dots (CQDs). One can also observe particles with sizes ranging from 100 to $200 \mathrm{~nm}$, which are due to the agglomeration during heating on $\mathrm{Al}$ foils. On the other hand, in Fig. 1b, it is observed that the nanoparticles of carbon have diameters of less than $10 \mathrm{~nm}$ prepared at $30^{\circ} \mathrm{C}$ and $70 \mathrm{~V}$. Even here, in Fig. 1c, we can observe carbon nanoparticles with diameters ranging from $10 \mathrm{~nm}$ to $50 \mathrm{~nm}$ - they were prepared at $30^{\circ} \mathrm{C}$ and $50 \mathrm{~V}$ at the same time. Anwar et al. [34], in 2019, used the hydrothermal method to prepare CQDs molecules using high temperature and they obtained nanoparticles with the size of less than $10 \mathrm{~nm}$ [35]. Also, in 2010, Zhang et al. [36] used the same method to elaborate CQDs with

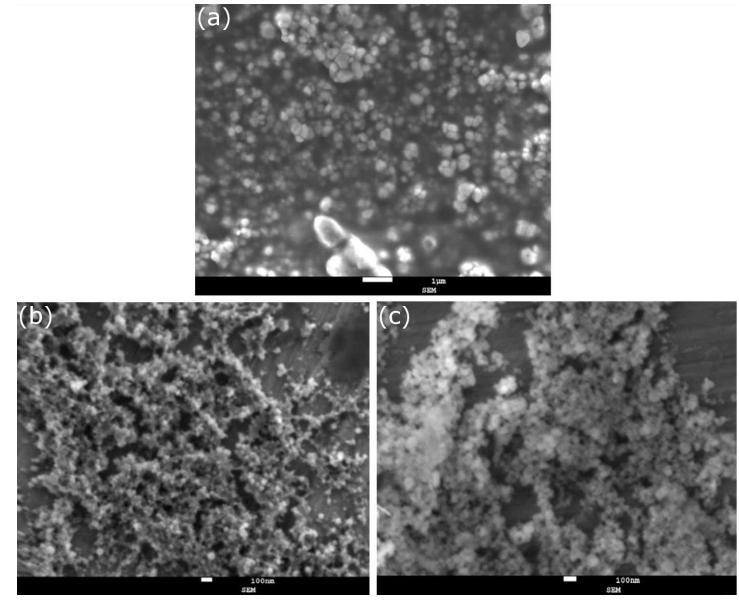

Fig. 1. SEM images of the prepared samples, (a) at $60^{\circ} \mathrm{C}, 70 \mathrm{~V}$ and $42 \mathrm{~h},(\mathrm{~b})$ at $30^{\circ} \mathrm{C}, 70 \mathrm{~V}$ and $42 \mathrm{~h}$, (c) $30^{\circ} \mathrm{C}$ and $50 \mathrm{~V}$ for $42 \mathrm{~h}$.

a size of $2 \mathrm{~nm}$. Likewise, Li et al. [37], in 2018, synthesized the graphene quantum dots of less than $6 \mathrm{~nm}$ which were doped by sulfur along with the reduced graphene oxide hybrids. In 2015, Yuxiang and Guangjie [38] prepared activated carbon fibers (ACFs) by chemical activation with $\mathrm{KOH}$ and they obtained nanoparticles mesopores with diameters ranging between 2 and $4 \mathrm{~nm}$ with a high surface area of $1371 \mathrm{~m}^{2}$.

\subsection{Raman analysis}

Raman spectra are presented in Fig. 2. Figure 2a shows a band located at about $1105 \mathrm{~cm}^{-1}$ related to a (C-O-C) band [39]. Another band, called the $\mathrm{D}$ band, is observed at $1319 \mathrm{~cm}^{-1}$ and corresponds to a graphite phonon qualified by several defects that activate the disorder of carbon nanomaterials [40]. A third peak at $1529 \mathrm{~cm}^{-1}$ defines the band of graphite $G$, linked to the existence of the carbon nanostructure of graphite, and the $1651 \mathrm{~cm}^{-1}$ frequency asserts vibrational vectors by defects [40]. Figure $2 \mathrm{~b}$ shows two different peaks, the first at $1332 \mathrm{~cm}^{-1}$ (D band), attributed to defects in the carbon system, and the second at $1579 \mathrm{~cm}^{-1}$ ( $\mathrm{G}$ band) of the vibration in the carbonaceous graphite bonding plane $(\mathrm{C}-\mathrm{C})$. Thus, as shown in Fig. 2c, two main peaks are observed: D and $\mathrm{G}$ bands located at $1328 \mathrm{~cm}^{-1}$ and $1581 \mathrm{~cm}^{-1}$, respectively. Our Raman results are comparable with the work of Hodkiewicz [41]: for carbon allotrope, graphite, composed entirely of (C-C) bonds, the main band has shifted from $1582 \mathrm{~cm}^{-1}$. In other materials, like multilayer graphene (MLG), the $\mathrm{D}$ band was located at $1349 \mathrm{~cm}^{-1}$ [42]. In general, the presence of disorder in the graphitic lattice is associated with the D band around $1350 \mathrm{~cm}^{-1}$ and the $\mathrm{G}$ band located around $1620 \mathrm{~cm}^{-1}$.

In another way, the ratio of $I_{D} / I_{G}$ is used to identify the nature of carbons prepared, see Table II. 

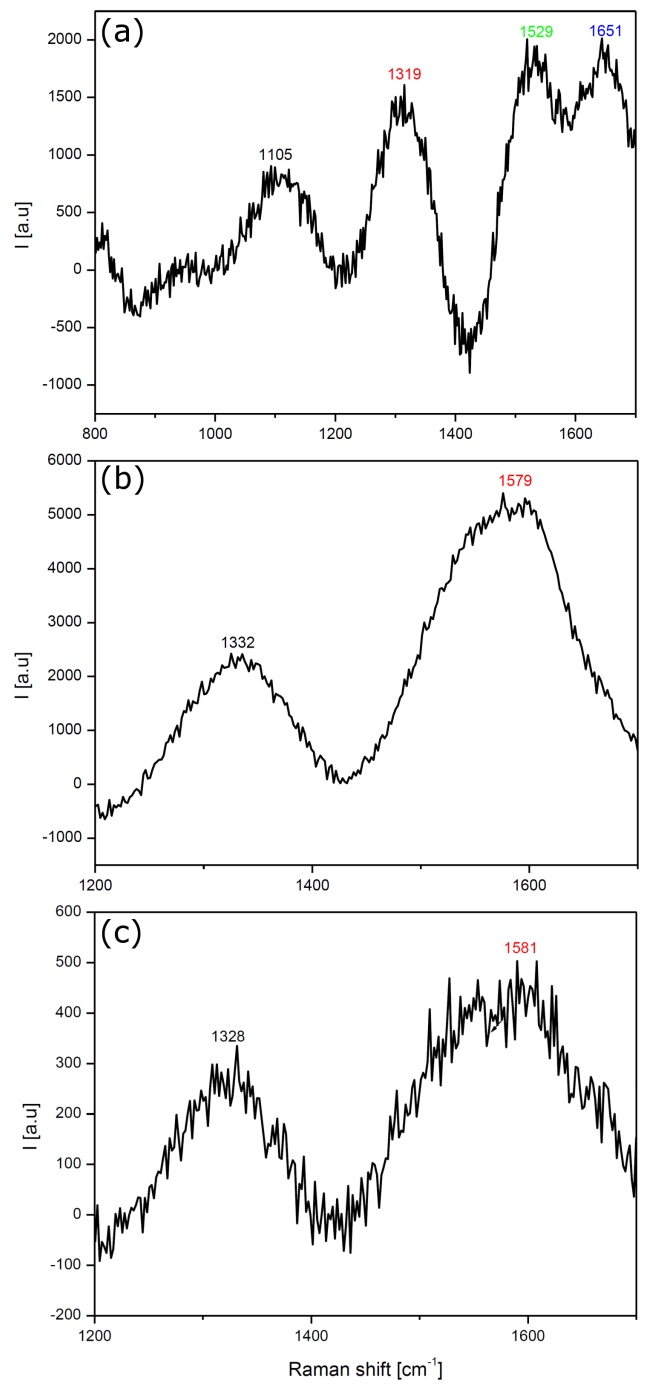

Fig. 2. Raman spectra of the three different samples; (a) $60^{\circ} \mathrm{C}, 70 \mathrm{~V}$ and $42 \mathrm{~h}$, (b) $30^{\circ} \mathrm{C}$ and $70 \mathrm{~V}$ at the same time and (c) $30^{\circ} \mathrm{C}, 50 \mathrm{~V}$ and $42 \mathrm{~h}$.

TABLE II

The calculated ratio intensities between $D$ and $G$ bands from the Raman spectra of the three samples.

\begin{tabular}{c|c|c|c|c}
\hline \hline Sample & $I_{D} / I_{G}$ & $\begin{array}{c}\mathrm{D} \text { band } \\
{\left[\mathrm{cm}^{-1}\right]}\end{array}$ & $\begin{array}{c}\mathrm{G} \text { band } \\
{\left[\mathrm{cm}^{-1}\right]}\end{array}$ & Identification \\
\hline $\mathrm{a}$ & 0.78 & 1319 & 1529 & $\mathrm{GO}$ \\
$\mathrm{b}$ & 0.45 & 1332 & 1579 & graphite \\
$\mathrm{c}$ & 0.60 & 1328 & 1581 & rGO
\end{tabular}

The $\mathrm{D}$ to $\mathrm{G}$ bands intensity ratio $I_{D} / I_{G}$ is typically used to estimate the size of the $s p^{2}$ domain of graphite-based materials as well as the ratio of $s p^{3} / s p^{2}$ hybrid carbon sites present in the carbonic materials.

In general, the $I_{D} / I_{G}$ ratio presents the degree of structural order. Therefore, when the structure of the material is more ordered, the $I_{D} / I_{G}$ ratio is more decreased.

\subsection{FTIR analysis}

The analysis of a FTIR spectroscopy device is shown in Fig. 3. FTIR curves of all samples are similar - they present exactly the same bands. The peaks in the range between $3320 \mathrm{~cm}^{-1}$ and $3330 \mathrm{~cm}^{-1}$ are for the formula of the group (O-H) [43]. Peaks from $2970 \mathrm{~cm}^{-1}$ to $2980 \mathrm{~cm}^{-1}$ present the diatomic carbon band $(\mathrm{C}-\mathrm{C})$ [43].

The bands from $2880 \mathrm{~cm}^{-1}$ to $2885 \mathrm{~cm}^{-1}$ reveal the existence of the hydrocarbons $(\mathrm{C}-\mathrm{H})$ band [43] while peaks in the range of $1390 \mathrm{~cm}^{-1}$ correspond to the carbon monoxide stretching $(\mathrm{C}-\mathrm{O})$ or the carboxylic acid $(\mathrm{C}-\mathrm{O}-\mathrm{O}-\mathrm{H})$ [43]. Different peaks varying between $1280 \mathrm{~cm}^{-1}$ and $1330 \mathrm{~cm}^{-1}$ indicate the presence of dicarbon monoxide with a formula of $(\mathrm{C}-\mathrm{O}-\mathrm{C})$, and the peaks ranging from $1040 \mathrm{~cm}^{-1}$ to $1090 \mathrm{~cm}^{-1}$ are for the carbon monoxide (C-O) [43] Our FTIR results may be compared with those of Zolfaghari et al. [44], who oxidized the commercial activated carbon (AC) with nitric acid and
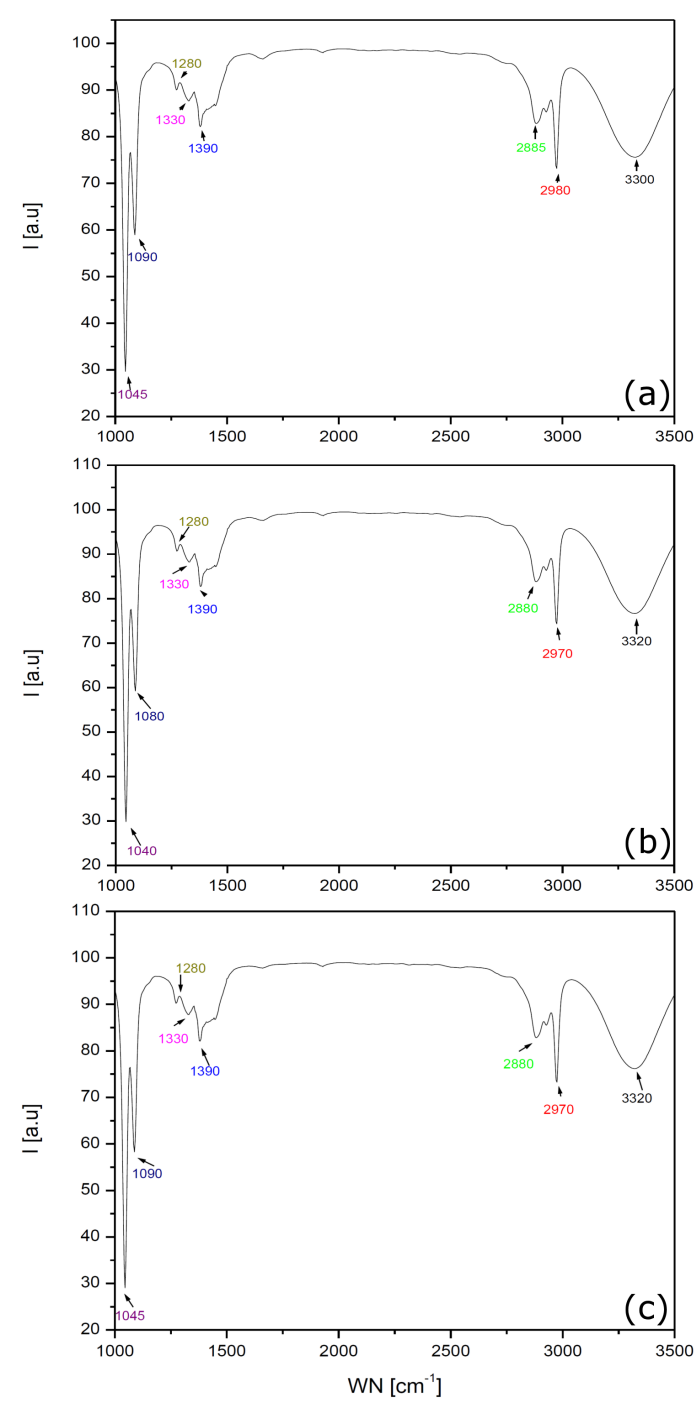

Fig. 3. Curves obtained by FTIR spectroscopy for the three samples (a), (b) and (c). 

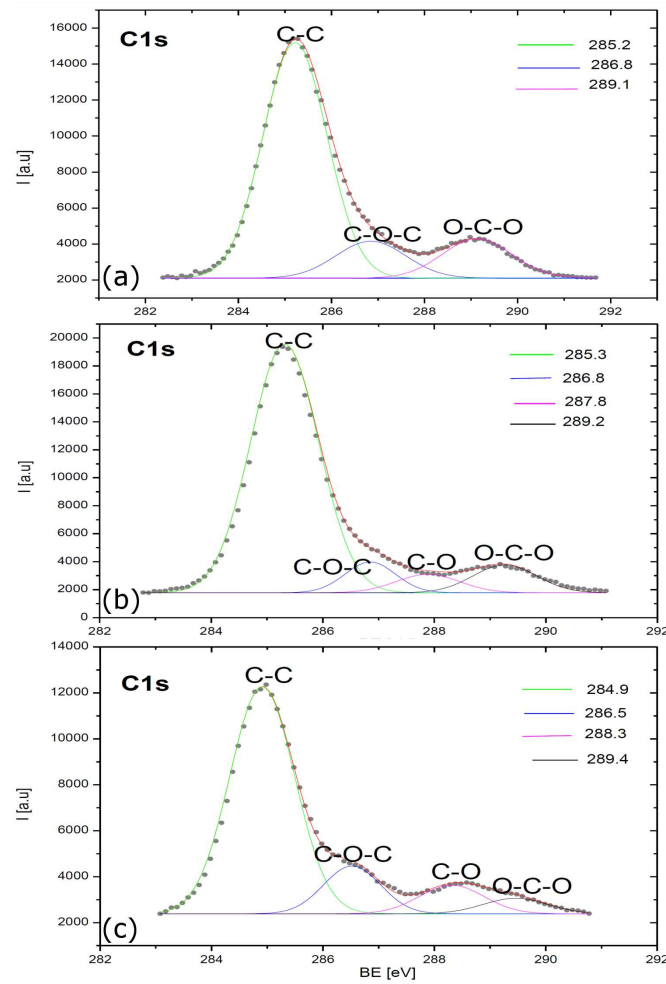

Fig. 4. The C $1 s$ curves obtained by XPS spectroscopy.

the $(\mathrm{C}-\mathrm{O})$ bands occurred around $1100-1700 \mathrm{~cm}^{-1}$ and with those of Aziz Fencan and al. [39], who in 2015 had two bands of $(\mathrm{O}-\mathrm{H})$ and $(\mathrm{C}-\mathrm{O})$ in the range of $2800-3200 \mathrm{~cm}^{-1}$ and $1650-1700 \mathrm{~cm}^{-1}$, respectively [45].

\subsection{XPS analysis}

The surface of carbon quantum dots was analyzed by X-ray photoelectron spectroscopy (XPS), as shown in Fig. 4. Chemical bonds of the three specimens were indicated and resulted in the first case (see Fig. 4a) with many binding energies; three intense peaks at 285.2, 286.8, and $289.1 \mathrm{eV}$, respectively, corresponded to the dicarbon (C-C), dicarbon monoxide $(\mathrm{C}-\mathrm{O}-\mathrm{C})$ and carbon dioxide $(\mathrm{O}-\mathrm{C}-\mathrm{O})$ bonds [46-48]. For the second condition (see Fig. 4b), we observed four-component peaks which represented $(\mathrm{C}-\mathrm{C})$ at $285.3 \mathrm{eV},(\mathrm{C}-\mathrm{O}-\mathrm{C})$ at $286.8 \mathrm{eV},(\mathrm{C}-\mathrm{O})$ at $287.8 \mathrm{eV}$ and $(\mathrm{O}-\mathrm{C}-\mathrm{O})$ for the binding energy of $289.2 \mathrm{eV}$ [46-48]. For the last condition (see Fig. 4c), the four peaks centered at 284.9, $286.5,288.3$, and $289.4 \mathrm{eV}$, representing the chemical binding of $(\mathrm{C}-\mathrm{C}),(\mathrm{C}-\mathrm{O}-\mathrm{C}),(\mathrm{C}-\mathrm{O})$, and $(\mathrm{O}-\mathrm{C}-\mathrm{O})$ [46-48].

The comparison of our XPS results with [49] showed many components of graphite such as: $(\mathrm{C}-\mathrm{C})$ at $284.4-285.1 \mathrm{eV},(\mathrm{C}-\mathrm{H})$ for $285.0-285.2 \mathrm{eV}$, (COOH or COOR) with 288.0-289.5 eV and (C-O) at $286.0-287.0 \mathrm{eV}$. Carbon black had three $\mathrm{C} 1 \mathrm{~s}$ components, $(\mathrm{C}-\mathrm{C}),(\mathrm{C}-\mathrm{O})$ and $(\mathrm{COOH} / \mathrm{COOR})$, which had the range of 284.3-284.8, 285.4-286.4, and 288.9-289.4 eV, respectively. Also, for the components of carbon nanotubes CNTs, they had: $(\mathrm{C}-\mathrm{C})$ of $284.7-286.0 \mathrm{eV},(\mathrm{C}-\mathrm{O})$ for $285.8-286.8 \mathrm{eV}$ and carbonates at $288.3 \mathrm{eV}$ [49].

The characterization of the nanocarbon structures by the Raman and XPS spectroscopies showed the appearance of carbon particles with oxygen. Oxygen proves that the carbons obtained are oxidized due to the emergence of graphite in ethanol, which has a chemical formula $\left(\mathrm{C}_{2} \mathrm{H}_{5} \mathrm{OH}\right)$. The ratio of $I_{D} / I_{G}$ has an estimated value of 0.45 for the graphite element and 0.60 for the rGO (reduced graphite oxide), while XPS confirms the presence of the carbon element and oxygen in the prepared sample. This study showed the distribution of carbonic surfaces analyzed by the SEM technique at the nanometric scale, which opens perspectives and objectives to be achieved in the field of energy storage in materials with a nanocarbon structure.

\section{Conclusion}

In this experimental research, we have used the electrochemical process as a mean of preparation of three samples. It shows that there is a possibility to create and develop particles in the form of nanostructured carbon. The synthesized carbon nanoparticles were characterized by SEM, Raman, FTIR, and XPS. The SEM images have shown spherical nanoparticles (CQDs) with sizes of less than $10 \mathrm{~nm}$ in conditions of $70 \mathrm{~V}$ and $30^{\circ} \mathrm{C}$ for $42 \mathrm{~h}$. The Raman spectroscopy shows the formation of nanoparticles of graphite based on nanocarbons: rGO and graphite oxide (GO). The FTIR and XPS analysis confirmed the existence of the carbon elementary composition.

\section{Acknowledgments}

We would like to thank the Research Materials Science and Applications Unit of Frères Mentouri Constantine 1 University and ENPC Constantine for the assistance and the experimental means offered.

\section{References}

[1] V. Campisciano, M. Grottadauria, F. Giacalone, ChemCatChem 11, 90 (2019).

[2] J.J. Vilatela, D. Eder, ChemSusChem 5, 456 (2012).

[3] C.N.R. Rao, K. Biswas, K.S. Subrahmanyam, A. Govindaraj, J. Mater. Chem. 19, 2457 (2009).

[4] Dang Sheng Su, S. Perathoner, G. Centi, Chem. Rev. 113, 5782 (2013).

[5] V. Georgakilas, J.A. Perman, J. Tucek, R. Zboril, Chem. Rev. 115, 4744 (2015).

[6] C. Liu, Y.Y. Fan, M. Liu, H.T. Cong, H.M. Cheng, M.S. Dresselhaus Science 286, 1127 (1999). 
[7] A.C. Dillon, K.M. Jones, T.A. Bekkedahl, C.H. Kiang, D.S. Bethune, M.J. Heben, Nature 386, 377 (1997).

[8] J.M. Blackman, Ph.D. Thesis, University of Nottingham, 2005.

[9] A. Chambers, C. Park, R.T.K. Baker, N.M. Rodriguez, J. Phys. Chem. B 102, 4253 (1998).

[10] A. Krueger, Carbon Materials and Nanotechnology, Wiley, 2010.

[11] Yongde Xia, Zhuxian Yang, Yanqiu Zhua, J. Mater. Chem. A 1, 9365 (2013).

[12] E. Boateng, C. Aicheng, Mater. Today 6, 100022 (2020).

[13] H. Nishihara, T. Kyotani, Adv. Mater. 24, 4473 (2012).

[14] J. Lee, J. Kim, T. Hyeon, Adv. Mater. 18, 2073 (2006).

[15] Y. Gogotsi, A. Nikitin, Haihui Ye, Wei Zhou, J.E. Fischer et al., Nat. Mater. 2, 591 (2003).

[16] E.N. Hoffman, G. Yushin, M.W. Barsoum, Y. Gogotsi, Chem. Mater. 17, 2317 (2005).

[17] N. Job, R. Pirard, J. Marien, J.-P. Pirard, Carbon 42, 619 (2004).

[18] Ying Wan, Yifeng Shi, Dongyuan Zhao, Chem. Mater. 20, 932 (2008).

[19] Shinae Jun, Sang Hoon Joo, Ryong Ryoo, M. Kruk, M. Jaroniec et al., J. Am. Chem. Soc. 122, 10712 (2000).

[20] F. D'Souza, O. Ito, Chem. Soc. Rev. 41, 86 (2011).

[21] Dang Sheng Su, R. Schlögl, ChemSusChem 3, 136 (2010).

[22] S. Marchesan, M. Prato, ACS Med. Chem. Lett. 4, 147 (2013).

[23] A. Fakharuddin, L. Schmidt-Mende, G. Garcia-Belmonte, R. Jose, I. MoraSero, Adv. Energy Mater. 7, 1700623 (2017).

[24] M. Man, S.V. Kumar, K.E. Anil, V. Gayathri, Energy Stor. 1, e35 (2019).

[25] C. Liu, Y.Y. Fan, M. Liu, H.T. Cong, H.M. Cheng, M.S. Dresselhaus, Science 286, 1127 (1999).

[26] B.K. Gupta, O.N. Srivastava, Int. J. Hydrog. Energy 26, 857 (2001).

[27] X.Y. Xu, R. Ray, Y.L. Gu, H.J. Ploehn, L. Gearheart et al., J. Am. Chem. Soc. 126, 12736 (2004).

[28] Y.-P. Sun, B. Zhou, Y. Lin, W. Wang, K.A.S. Fernando et al., J. Am. Chem. Soc. 128, 7756 (2006).
[29] X. Li, H. Wang, Y. Shimizu, A. Pyatenko, K. Kawaguchi, N. Koshizaki, Chem. Commun. 47, 932 (2011).

[30] X. Sun, Y. Lei, TrAC Trend. Anal. Chem. 89, 163 (2017).

[31] J. Deng, Q. Lu, N. Mi, H. Li, M. Liu, M. Xu et al., Chem. Eur. J. 20, 4993 (2014).

[32] X. Wang, Y. Feng, P. Dong, J. Huang, Front. Chem. (2019).

[33] G. Sdanghi, R.L.S. Canevesi, A. Celzard, M. Thommes, V. Fierro, J. Carbon Res. 6, 46 (2020).

[34] S. Anwar, H. Ding, M. Xu, X. Hu, Z. Li, J. Wang et al., ACS Appl. Bio Mater. 2, 2317 (2019).

[35] Y. Xia, Z. Yong, Y. Zhu, Materials Chemistry A 1, 9365 (2013).

[36] Bing Zhang, Chun-yan Liu, Yun Liu, Eur. J. Inorg. Chem. 2010, 4411 (2010).

[37] F. Li, L. Sun, Y. Luo, M. Li, Y. Xu et al., RSC Adv. 8, 19635 (2018).

[38] Y. Huang, G. Zhao, Holzforschung 70, 0051 (2015).

[39] Raman Spectroscopy for Analysis and Monitoring, HORIBA Jobin Yvon Raman application note.

[40] C. Castiglioni, M. Tommasini, Opt. Pura Apl. 40, 169 (2007).

[41] J. Hodkiewicz, "Characterizing Carbon Materials with Raman Spectroscopy", Thermo Fisher Scientific, application note 51901, 2010.

[42] L. Bokobza, J.L. Bruneel, M. Couzi, Vibrat. Spectrosc. 74, 57 (2014).

[43] V. Tucureanu, A. Matei, A.M. Avram, Crit. Rev. Anal. Chem. 46, 502 (2016).

[44] G. Zolfaghari, A. Esmaili-Sari, H. Younesi, R.R. Baydokhti, in: Proc. 2nd Int. Conf. on Environmental Science and Technology, IPCBEE, Vol. 6, IACSIT Press, Singapore 2011.

[45] A. Şencan, M. Kılıç, J. Chem. 2015, 651651 (2015).

[46] Huynh Ngoc Tien, Seung Hyun Hur, Phys. Status Solidi Rapid Res. Lett. 6, 379 (2012).

[47] F. Xie, S.H. Qi, D. Wu, Express Polym. Lett. 10, 470 (2015).

[48] S. Sarkar, D. Gandla, Y. Venkatesh, P.R. Bangal, S. Ghosh et al. Phys. Chem. Chem. Phys. 18, 21278 (2016).

[49] Xiangnan Chen, Xiaohui Wang, De Fang, Fuller. Nanotub. Carbon Nanostruct. 28, 1048 (2020). 